九州大学学術情報リポジトリ

Kyushu University Institutional Repository

\title{
ITPA protein, an enzyme that eliminates deaminated purine nucleoside triphosphates in cells
}

Sakumi, Kunihiko

Division of Neurofunctional Genomics, Department of Immunobiology and Neuroscience, Medical Institute of Bioregulation, Kyushu University

Abolhassani, Nona

Division of Neurofunctional Genomics, Department of Immunobiology and Neuroscience, Medical Institute of Bioregulation, Kyushu University

Behmanesh, Mehrdad

Department of Genetics, School of Biological Sciences, Tarbiat Modares University

\section{Iyama, Teruaki}

Division of Neurofunctional Genomics, Department of Immunobiology and Neuroscience, Medical Institute of Bioregulation, Kyushu University

他

http://hdl. hand le. net/2324/26105

出版情報: Mutation Research - Genetic Toxicology and Environmental Mutagenesis. 703 (1)， pp. 43-50, 2010-11-28. Elsevier

バージョン:

権利関係: (C) 2010 Elsevier B.V. 
ITPA protein, an enzyme that eliminates deaminated purine nucleoside triphosphates in cells

Kunihiko Sakumi", Nona Abolhassani, Mehrdad Behmanesh ${ }^{1}$, Teruaki lyama, Daisuke Tsuchimoto, Yusaku Nakabeppu

Division of Neurofunctional Genomics, Department of Immunobiology and Neuroscience, Medical Institute of Bioregulation, Kyushu University, Fukuoka 812-8582, Japan

1 Department of Genetics, School of Biological Sciences, Tarbiat Modares University, P. O. Box 14155-154, Tehran, Iran

"Corresponding author: K Sakumi, 3-1-1, Maidashi, Higashi-ku, Fukuoka 812-8582, Japan. Tel: +81 92642 6802; Fax: +81 92642 6804; E-mail: sakumi@bioreg.kyushu-u.ac.jp
Abbreviations:
ITP: inosine triphosphate
dITP: deoxyinosine triphosphate
Py: pyrimidine
MTH1: mutT homolog 1
6TG: 6-thioguanine 


\section{Abstract}

Inosine triphosphate pyrophosphatase (ITPA protein) (EC 3.6.1.19) hydrolyzes deaminated purine nucleoside triphosphates, such as ITP and dITP, to their corresponding purine nucleoside monophosphate and pyrophosphate. In mammals, this enzyme is encoded by the Itpa gene. Using the Itpa gene-disrupted mouse as a model, we have elucidated the biological significance of the ITPA protein and its substrates, ITP and dITP. Itpa ${ }^{-/-}$mice exhibited peri- or postnatal lethality dependent on the genetic background. The heart of the Itpa ${ }^{-/}$ mouse was found to be structurally and functionally abnormal. Significantly higher levels of deoxyinosine and inosine were detected in nuclear DNA and RNA prepared from Itpa ${ }^{-/}$embryos compared to wild type embryos. In addition, an accumulation of ITP was observed in the erythrocytes of Itpa $a^{-/-}$mice. We found that Itpa ${ }^{-/-}$primary mouse embryonic fibroblasts (MEFs), which have no detectable ability to generate IMP from ITP in whole cell extracts, exhibited a prolonged population-doubling time, increased chromosome abnormalities and accumulation of single-strand breaks in their nuclear DNA, in comparison to primary MEFs prepared from wild type embryos. These results revealed that (1) ITP and dITP are spontaneously produced in vivo, and that (2) accumulation of ITP and dITP is responsible for the harmful effects observed in the Itpa ${ }^{-/-}$mouse. In addition to its effect as the precursor nucleotide for RNA transcription, ITP has the potential to influence the activity of ATP/GTP-binding proteins. The biological significance of ITP and dITP in the nucleotide pool remains to be elucidated.

Key words:

ITP; dITP; ITPA gene; inosine triphosphate pyrophosphatase; inosine; deoxyinosine 


\section{Introduction}

To control the quality of nucleotide pools, organisms possess a number of nucleoside triphosphate (NTP) pyrophosphatases which hydrolyze non-canonical nucleoside triphosphates to their corresponding monophosphates. Recently, many kinds of NTP pyrophosphatases have been reported by various groups who undertook a structure-based approach [1], a modified nucleotide-resin affinity-based approach [2, 3 in the same issue] as well as an approach based on genomic search techniques [4,5]. These enzymes are categorized as house-cleaning (or nucleotide-pool-sanitizing) NTP pyrophosphatases and are grouped within four structural super-families: MutT-related (Nudix) hydrolases, trimeric dUTPase, ITPase (HAM1/Maf) and all-alpha NTP pyrophosphatases (MazG) [6].

ITPase (EC 3.6.1.19) is an enzyme with the activity of NTP pyrophosphohydrolase, and preferentially hydrolyzes deaminated purine nucleoside triphosphates, such as ITP, dITP, XTP and dXTP, to their corresponding nucleoside monophosphate and pyrophosphate $[1,4,5,7$, Behmanesh et al, unpublished]. This enzyme has been studied for decades, and is known by different names, such as inosine triphosphate pyrophosphohydrolase, inosine triphosphate pyrophosphatase, inosine triphosphatase as well as others. ITPase is encoded by the Itpa gene in mammals [4,5], the $r d g B$ (recombination-dependent growth, locus B) gene in Escherichia coli $[7,8]$, and the HAM1 (6-N-Hydroxylaminopurine Sensitivity and Mutagenesis) gene in Saccharomyces cerevisiae [9]. These enzymes fall within the ITPase family as they possess the HAM1p domain in their structure [6]. The 3D-structures of archaean and mammalian enzymes were determined by X-ray crystallography $[1,10]$. The ITPA protein does not distinguish between ITP and dITP, since there is no strong interaction between the protein and the 2 '-oxygen of the sugar ring of the substrate nucleotides [1,10]. The ITPA protein acts as a dimer, and requires $\mathrm{Mg}^{2+}$ ion and dithiothreitol for maximal enzyme activity [4,11]. Previously, it has been reported that the $\mathrm{K}_{M}$ values of ITPA protein for dITP and other substrates are in the several hundred micro molar range (for example, 0.31 $\mathrm{mM}$ of dITP for human ITPA protein) $[1,4,12]$. Considering substrate inhibition 
[11], which is observed in the ITPA reaction at a dITP concentration above 250 $\mu \mathrm{M}$, Burgis and Cunningham recently determined that the $K_{M}$ values of mouse and human ITPA protein for dITP are 25 and $33 \mu \mathrm{M}$, respectively [7]. The gene has been found in many kinds of organisms from virus, bacteria to human $[1,4-9,13,14]$. However, the phenotypes of gene-disrupted mutants are different among species (Table 1). In E. coli, a mutant of the rdgB gene encoding ITP pyrophosphatase has been found to be viable but exhibits a synergistic lethality with the recA or recBC mutation, hyper-recombination and SOS-induced phenotype $[7,8,15]$. In the case of human ITPA deficiencies, no major phenotype has been reported, except for an abnormal accumulation of ITP in erythrocytes and an aberrant sensitivity to nucleoside antimetabolite drugs [16-19]. To avoid any confusion in this review, we describe the enzyme activity as ITP pyrophosphatase activity, and the protein, by the symbol of each gene.

Using the Itpa gene-disrupted mouse as a model, we will discuss the biological significance of the ITPA protein and its substrates, ITP and dITP.

\section{The Itpa gene-disrupted mouse (Itpa ${ }^{-/-}$mouse)}

\subsection{The mouse Itpa gene}

The mouse Itpa gene consists of 8 exons and spans a region of about 13.8 $\mathrm{kb}$ on chromosome 2 [5]. Three pseudogene-like sequences were found in the mouse genome [5]. Different sizes of transcripts have been reported in both human and mouse Itpa genes [5,20]. Mouse ITPA protein consists of 198 amino acid residues and has a molecular weight of 21,883 daltons. Its amino acid sequence is $89.9 \%$ identical to that of the human ITPA protein (194 a.a.) [5]. An expression profile of the Itpa gene in adult mouse tissues examined by Northern blotting showed that the Itpa gene was expressed in all tissues examined, however, its level varied significantly among tissues, with strong expression observed in testis, brain and thymus [5]. The genomic sequence revealed that the mouse Itpa gene has a TATA-less promoter with an initiator consensus sequence of PyPyANT/APyPy (CTACTTC), just upstream of the $5^{\prime}$ end of the longest Itpa transcript, indicating that the Itpa gene may be a house-keeping gene [5]. The level of Itpa mRNA is affected by the cell cycle stage; it is highest 
just before S-phase, and low in the quiescent state [5]. In extracts prepared from mouse brain and liver, only a single band corresponding to a polypeptide with a molecular weight of $22 \mathrm{kDa}$ was detected with an anti-ITPA serum. The ITPA protein exists mainly in cytoplasm, and is not detected in the mitochondrial fraction [5, Sakumi et al, unpublished result].

\subsection{The Itpa gene-disrupted mouse (Itpa ${ }^{-/}$mouse)}

Recently, we reported the production and characterization of the Itpa gene-disrupted mouse [21]. This mouse possesses a disrupted-Itpa gene in which exons 2-4 that encode Val23-lle88 of the mouse ITPA protein are replaced with the pollI-neo cassette. Although an aberrant Itpa transcript was detected in the Itpa ${ }^{-/}$mouse, null expression of the ITPA protein in this mouse was confirmed by western blotting as well as by an ITP pyrophosphatase assay (Fig. 1A).

The Itpa ${ }^{+/}$mouse was indistinguishable from its Itpa ${ }^{+/+}$littermates with respect to size, viability, fertility and behavior. With a C57BI/6J genetic background, Itpa ${ }^{-/}$mouse exhibits a perinatal lethality [22]. However, given a $129 \mathrm{SvEv} / \mathrm{C} 57 \mathrm{BI} / 6 \mathrm{~J}$ mixed genetic background, about $10 \%$ of the offspring obtained by the mating of Itpa ${ }^{+/}$mice had the Itpa ${ }^{-/}$genotype [21]. The newborn Itpa ${ }^{-/}$mice showed growth retardation and died before weaning, although there was a significant amount of milk in their stomachs (Fig. 1B). Prior to death, the Itpa ${ }^{-/}$mouse exhibited ataxia, abnormal breathing, and heart abnormalities. On pathological analysis, the Itpa $a^{-/}$mouse showed such features as immature hair follicles, hyperkeratosis of the forestomach, decreased extramedullary hematopoiesis in liver and spleen, and germ cell hypoplasia in testis, in addition to hypoplasia of the heart [21].

The heart of the Itpa ${ }^{-/}$mouse was smaller and immature, especially in terms of the ventricular regions (Fig. 1C). Analysis of a 10-day-old Itpa ${ }^{-/}$mouse heart showed that both ventricular chamber walls were thinner than those of the Itpa ${ }^{+/+}$mouse. Striated staining of desmin corresponding to the Z-disc was absent in the Itpa ${ }^{-/}$heart and disorganization of myocardial fibers was observed [21]. On ultrastructural analysis of Itpa ${ }^{-\%}$ mouse cardiomyocytes, it was evident that the number of sarcomeres was decreased and that the sarcomeric structure 
was broken and disorganized (Fig. 1C). The shape of the mitochondria was changed although the inner and outer membrane structure seemed normal. We did not find apoptotic cardiomyocytes nor symptoms of myocardial infarction in the heart of the Itpa ${ }^{-/}$mouse. Its cardiac performance as observed by echocardiography was also impaired; movement of the Itpa ${ }^{-/}$mouse heart was unsynchronized and jerky [21]. These results indicate that an ITPA-deficiency causes disruption of the sarcomeric structure and dysfunction of cardiomyocytes.

\subsection{ITP detected in the Itpa ${ }^{-/}$mouse}

Under ITPA-deficient conditions, ITP is expected to accumulate in the nucleotide pool and the accumulated ITP to be incorporated into the RNA. It has been shown that ITP is indeed accumulated in amounts corresponding to about $10 \%$ of the ATP molecules in the nucleotide pool of Itpa ${ }^{-/}$mouse (10-days-old) erythrocytes (Fig. 1D) [21]. No ITP was detected in erythrocytes of either the Itpa $^{+/+}$or Itpa ${ }^{+/}$mouse. As for organs including the heart, however, no ITP was detected in the nucleotide pool of the Itpa- mouse. One possibility is that the accumulated ITP is spent in its incorporation into the RNA by transcription, except in erythrocytes where transcription does not occur. Alternatively, rapid degradation of nucleotides may prevent detection of minor nucleotide species in tissues. In the case of RNA, IMP was detected in nuclease P1-digested RNA of Itpa ${ }^{-/}$mouse heart, and the amount was equivalent to about $1 \%$ of the AMP [21]. These results clearly showed that ITP was indeed produced in mouse cells, and that ITPA protein degraded the deaminated nucleotides to maintain the quality of the ATP pool.

It is well known that quality control of the nucleotide pool is important for DNA and RNA synthesis [23-25]. By way of analogy to 8-oxo-dGTPase (MTH1) function [26], the ITPA protein has been considered to prevent dITP-induced mutagenesis. However, because the $\mathrm{K}_{\mathrm{M}}$ value of ITPase to its substrate is not particularly small ( $25 \mu \mathrm{M}$ for dITP [7]) as compared to the size of the dNTP pool (13 $\mu \mathrm{M}$ for dATP [27]), it is more likely that ITP, a deaminated product of ATP, which is the most abundant nucleotide in the nucleotide pool (2.8 $\mathrm{mM}$ [27]), is a physiological substrate for ITPA protein in mammalian cells. It is known that ITP 
inhibits certain kinds of biochemical reactions that require GTP or ATP, such as microtuble polymerization [28,29] and contraction of actomyosin in muscle [30].

ATP, a multifunctional nucleotide and the most abundant in the nucleotide pool, plays a fundamental role in a wide variety of cellular processes, including RNA synthesis, energy translation, signal transduction, cytoskeleton remodeling, and muscle contraction. In the case of cardiac function, a number of sarcomeric proteins require ATP for their normal activities. Oxidative deamination of adenine at C-6 converts ATP to ITP. Because ITP retains a molecular structure similar to that of ATP, it can act as an aberrant substrate replacing ATP in some biological processes. For example, it has been shown that Mg•ITP-bound actomyosin has a greatly reduced shortening velocity and rate of force recovery as compared to the Mg•ATP-bound form, and exhibits disordered striations during activation in vitro [30].

If ITP were to successfully compete with the ATP molecule, then either (1) ITP would have to have a much higher affinity to a target protein than ATP, (2) the number of ITP molecules would have to be greater than that of ATP, or (3) the number of ATP molecules would be inadequate for the number of target proteins, which may function cooperatively as do sarcomeric proteins [31]. One likely possibility is that, during cardiac development of the Itpa $^{-/-}$mouse, accumulated ITP competes with ATP, which is required for actomyosin function in the sarcomere [21]. The random binding of a few ITP molecules to actomyosin results in asynchronous sarcomeric movements, which may cause a degradation of the striated pattern of the sarcomere and destroy its well-organized structure, which is essential for heart function.

To explain the phenotypes of the ITPA-deficient mouse, we can consider the three pathways shown in Fig. 2; (I) via dITP, which is incorporated into DNA, (II) via ITP, which is incorporated into RNA, and (III) via ITP, which exists as a free nucleotide and acts as an agonist or antagonist to ATP/GTP-binding proteins. In the second case, we have observed that IMP is accumulated in the RNA of Itpa $^{-/}$mouse tissue. It is likely that the accumulated inosine nucleotides lead RNA species to be altered in coding property and structure, resulting in the production of defective proteins, or in destabilization of RNA-containing 
complexes such as the ribosome. In either case, it is necessary for cells to eliminate ITP from their ATP pool via the ITPA protein in order to keep cells healthy. Our findings with the Itpa ${ }^{-/}$mouse are in strong agreement with the hypothesis that the ITPA protein functions to exclude ITP from the ATP pool and to protect cells from the harmful influence of deaminated purine nucleotides [21].

2.4. Deoxyinosine ( $\mathrm{dl})$ and inosine are detected in the DNA and RNA of the Itpa ${ }^{-/-}$ mouse embryo and embryonic fibroblast.

As shown in Fig. 2, the dITP molecule is also expected to be incorporated into DNA of the Itpa ${ }^{-/}$mouse. Using liquid chromatography coupled with tandem mass spectrometry (LC-MS/MS) as a detection system, we quantified the amounts of deoxyinosine (dl) and inosine nucleotides in the DNA and RNA of Itpa ${ }^{-/}$mouse embryo (E14.5), respectively [22]. The Itpa ${ }^{-/}$embryo contained a significant amount of $\mathrm{dl}$ in its nuclear DNA. The amount of $\mathrm{dl}$ residue detected in Itpa ${ }^{-/}$embryos (20.1 $\pm 4.8 \mathrm{dl}$ residues per $10^{6}$ nucleosides) was more than eight times that measured in Itpa ${ }^{+/+}$embryos $\left(2.34 \pm 0.76 \mathrm{dl}\right.$ residues per $10^{6}$ nucleosides). These amounts correspond to about $2 \times 10^{4} \mathrm{dl}$ residues per single wild type cell, and more than $10^{5} \mathrm{dl}$ residues per single Itpa ${ }^{-/}$cell in terms of their nuclear DNAs. These results indicate that both spontaneous dITP generation and incorporation of the dITP into DNA occur in the Itpa ${ }^{-/}$cell. We also confirmed the presence of a significantly increased accumulation of inosine (567.3 \pm 41.4 residues per $10^{6}$ guanosine) in cellular RNA prepared from Itpa ${ }^{-/}$embryos compared to those from 1 tpa ${ }^{+/+}\left(10.5 \pm 1.50\right.$ residues per $10^{6}$ guanosine $)$ and Itpa $^{+/}$(11.4 \pm 1.07 residues per $10^{6}$ guanosine) embryos [22]. The amount of inosine accumulated in RNA of the Itpa ${ }^{-/}$embryo was more than 50 times higher than that of the wild type.

Itpa ${ }^{-/}$primary mouse embryonic fibroblasts (pMEFs), which were established from Itpa ${ }^{-/}$mouse embryos, are characterized by a prolonged doubling time, G2/M arrest and a higher frequency of chromosomal abnormality [22]. In the Itpa ${ }^{-/}$pMEFs, single-strand DNA breaks are increased in nuclear DNA as are chromosomal abnormalities such as chromatid/chromosome gaps or breaks and premature centromere separation. It is likely that these abnormalities 
cause G2/M arrest, thus suppressing cell proliferation as observed in the Itpa ${ }^{-/-}$ pMEFs. These ITPA deficiency-caused features may result in severe cellular dysfunction with growth retardation and late embryonic lethality.

How did the single-strand DNA breaks and chromosomal abnormalities occur in the Itpa- pMEFs? It is likely that these breaks are produced in the DNA repair process during which deoxyinosines accumulate in nuclear DNA. At least two enzymes are known to be involved in the excision repair of dl; the mammalian homolog of endonuclease $\mathrm{V}$ (endoV) [32], which cleaves at the second phosphodiester bond 3' to the $\mathrm{dl}$, and methylpurine DNA glycosylase (MPG/AAG), which excises hypoxanthine [33-35], the base component of $\mathrm{dl}$. Mismatch repair proteins are another possible cause of single-strand DNA breaks. Since an aberrant base pair of 6-thioguanine (6TG):T is known to be recognized by mammalian MutS $\alpha$ proteins [36,37], a dl:dT mispair might be recognized by the proteins.

It is noteworthy that exposure of peripheral lymphocytes to ITP or IDP in culture was reported to cause such chromosomal aberrations as chromatid breaks and gaps [38] as well as sister chromatid exchange [39]. Although the precise mechanism responsible for the chromosomal aberrations by ITP or IDP is not known, exposure to a high concentration of ITP or IDP may result in an increase in the $\mathrm{dl}$ level in nuclear DNA, thus increasing the frequency of single-strand DNA breaks and chromosomal abnormality as observed in Itpa ${ }^{-/-}$ primary MEFs. Moreover, both ITPA deficiency and exposure to ITP or IDP were found to increase premature centromere separation $[22,38]$. These chromosomal abnormalities may be due to an increased level of ITP in the nucleotide pool. Since sister chromatid cohesion is accomplished via a cohesin complex composed of Rad21, Smc1a, Smc3, and two Scc3 orthologues, SA1 and SA2 [40,41] through a reaction requiring ATP, ITP may compete with ATP and disrupt establishment of sister chromatid cohesion, thus resulting in premature centromere separation and inappropriate chromatid separation.

\section{Source of ITP and dITP, and their metabolic pathways in the cell}


Using ITPA-deficient mice and MEFs, we confirmed that (1) ITP and dITP are spontaneously produced in vivo, and (2) the amounts of inosine nucleotides in RNA and DNA are increased under ITPA deficient-conditions. These findings raise several new questions. What is the source of ITP and dITP in vivo? Does spontaneous or enzymatic deamination of ATP and dATP occur or are ITP and dITP produced as metabolites derived from IMP? How do the nucleotides function in these mice and inflict damage at the cellular and macroscopic level? Is the mechanism common to different species?

The amount of ITP in the nucleotide pool is dependent on an equilibrium between synthesis and degradation. The degradation involves transcription and enzymatic hydrolysis. ITP is known to be incorporated into RNA by RNA polymerase II and III, however, it results in an inhibition of the elongation reaction [25,42]. ITP is incorporated by human RNA polymerase II, and is inserted with the same $K_{M}$ and $V_{\max }$ as GTP at the same template position [25]. However, the transcriptional proofreading mechanism was found to inhibit the elongation of transcription at the IMP position. The levels of ITP and dITP are mainly controlled through the activity of the ITPA protein, which varies among individuals in human populations [16-19]. Recently, an enzyme with IDP/dIDP hydrolyzing activity has been identified [22,43]. Intracellular concentrations of ITP and dITP are restricted by these enzymes to maintain the cell in a healthy state.

The metabolic pathway used to produce ITP is currently not well known as yet (Fig. 3). As with pathways from IDP to ITP and dIDP to dITP, it is known that nucleoside diphosphate kinase is efficient at catalyzing the reaction with ATP as a phosphate group donor [44]. However, according to the KEGG purine metabolic pathway and based on the results of the previous authors, the enzyme that produces IDP from IMP is missing [45]. In E.coli, it has shown that guanylate kinase may catalyze the reaction in a certain case $[46,47]$. As for eukaryotic cells, there are two conflicting reports; one group using rabbit erythrocytes showed that there is no enzyme for converting IMP to IDP [48], while the other detected IDP production after ${ }^{14} \mathrm{C}$-labeled hypoxanthine was applied [49]. It is possible that different pathways are used in different species. The gene of the enzyme, which efficiently converts IMP to IDP under physiological conditions, has not yet been 
identified in mammals. As another possibility, ITP can be formed by deamination of the ATP molecule, which occurs spontaneously or by enzymatic reaction [50]. Karran and Lindahl [51] have shown that spontaneous deamination of an adenine base occurs in DNA. This reaction is enhanced under conditions of a low $\mathrm{pH}$ in the presence of nitrite, conditions similar to those that are found inside the stomach. Although ATP deaminase activity was found in Microsporum audouini [52], its existence has not yet been reported in mammalian cells.

In the case of ITPA-deficient mouse erythrocytes, we detected a large amount of ITP molecules corresponding to $10 \%$ of that of ATP [21]. Production and accumulation of the ITP molecules occurred during a few weeks (from the embryonic stage to 10 days after birth). Whether by a chemical or enzymatic reaction, a significant amount of the ITP can be produced in the cell if ITPA protein is absent. It is possible that erythrocytes possess an as yet unidentified enzyme with IMP kinase activity which converts IMP to IDP by ATP hydrolysis (Fig. 3). Mammalian adenylate and guanylate kinases are the candidate enzymes which have reported to be able to phosphorylate IMP in vitro $[53,54]$. Because the concentration of ATP is high, the reaction may proceed even if the concentration of IMP is low. If the enzyme does not exist [48], it is more likely that the deaminated ATP is a source of ITP, as compared to the product of the enzymatic phosphorylation of IDP. This is because the amounts of IDP and IMP observed in the Itpa ${ }^{-/}$erythrocytes are small compared to that of ITP (Fig. 1D) [21]. The abundance of IMP in nucleotide pool is variable in tissues of the wild type mouse; IMP is hardly detectable in erythrocytes, readily detectable in liver, and muscle contains almost the same amount of IMP as ATP (unpublished result, Sakumi et al). ITP in muscle might be produced through the IMP-IDP pathway.

It is clear that a significant amount of dITP is produced and incorporated into DNA in cells, since dl was detected in the DNA of ITPA ${ }^{-/}$embryos and primary MEFs [22]. As with ITP, we can consider two pathways for the production of dITP in vivo, namely, deamination of dATP and metabolic conversion of IDP (Fig. 3). As for the pathway used in converting IDP to dIDP, we could not find any report confirming whether mammalian ribonucleotide reductase is able to catalyze the reaction. Ribonucleotide reductase is known to 
have strict substrate specificity [55]. However, because 6-TG and other nucleoside analogues are incorporated into DNA [56], IDP is also a potential substrate for the enzyme. If IDP is the substrate of ribonucleotide reductase in vivo, controlling the amount of IDP is very important for quality control of the dNTP pool since dIDP is phosphorylated by nucleotide diphosphate kinase to produce dITP [44]. Recently, NUDT16 protein has been reported to possess IDP/dIDP phosphohydrolase activity (Fig. 3, [22,43]). The enzyme may have a role in preventing the increase of dITP in the dNTP pool.

\section{Biological significance of ITP and dITP}

We now know that significant amounts of inosine and deoxyinosine nucleotides are produced in the nucleotide pool, and are found in the RNA and DNA of mammalian cells [22]. The amount of $\mathrm{dl}$ in DNA of Itpa ${ }^{-/}$mouse cells is much more than that of 8-oxodG in DNA of Ogg1,Mth1 double-knockout $\left(\operatorname{Ogg} 1^{-/}, M\right.$ th $\left.1^{-/}\right)$mouse cells [57].

To evaluate the biological significance of deaminated purine nucleoside triphosphates such as ITP and dITP, we have to consider the three pathways shown in Fig. 2. In the first, dITP is produced in cells, and incorporated into DNA by DNA polymerases. Deoxyinosine in DNA may cause cellular dysfunctions, such as mutations and strand breaks, the latter occurring as part of the DNA repair pathways $[8,32-35,46]$. In the second pathway, ITP is produced and incorporated into RNA during transcription [25]. The incorporated inosine might affect the structure and function of RNA and RNA-protein complexes such as ribosomes, or may result in a mutated protein through aberrant translation. In the third pathway, ITP functions as a free nucleotide and acts as an agonist or antagonist to ATP/GTP-binding proteins [28-30].

In $E$. coli, the lethality of $r d g B$ rec $A$ or $r d g B$ rec $B C$ double mutants, the former encoding ITP pyrophosphatase, is suppressed by the inactivation of endonuclease V [8], which cleaves at the second phosphodiester bond 3' to the lesion, a deaminated adenosine, thus initiating alternative excision repair [32]. It is likely that an ITP pyrophosphatase deficiency in E.coli results in the accumulation of dITP in the nucleotide pool, thus causing an increased 
accumulation of $\mathrm{dl}$ in the DNA. Excision repair initiated by endonuclease $\mathrm{V}$ leads to chromosomal fragmentation in $\operatorname{rec} A$ and $\operatorname{rec} B C$ mutants [8]. The hyper-recombination and SOS-induced phenotype of the $r d g B$ single mutant is also reversed by the inactivation of endonuclease $V$ [58]. These observations strongly suggest that ITPA deficiency in mouse cells also causes chromosomal abnormality [22].

As observed in the Itpa ${ }^{-/}$mouse, a deficiency in ITP degradation leads to a cardiomyopathy-like phenotype, which is known to be mainly caused by mutations of sarcomeric protein-encoding genes [59]. It is clear that maintenance of the quality of the ATP pool is important for sarcomere organization in the heart. Since ITP has structural similarity not only to ATP but also to GTP, ITP has a potential to affect the functions of GTP binding/hydrolyzing proteins. ITP pyrophosphatase activity should be important in keeping biochemical processes in cells functioning properly.

In the case of human ITPA deficiency, however, no major phenotype has been reported except for an abnormal accumulation of ITP in erythrocytes and an aberrant sensitivity to nucleoside antimetabolite drugs such as azathioprine and ribavirin [16-19]. Sumi et al found that the P32T mutation is responsible for human ITPA deficiency, and proposed a relationship between this deficiency and an increased sensitivity to the toxicity of nucleoside analogue drugs [17]. They suggested that the ITP level in ITPA-deficient human erythrocytes may represent $10 \%-25 \%$ of the ATP pool, which is similar to the amount of ITP observed in the Itpa ${ }^{-/}$mouse [21]. To explain the difference in the phenotypes of ITPase-deficient mice and humans, we considered two hypotheses. One is that there is another compensational mechanism in human cells used in excluding ITP from the ATP pool, other than that involving ITPA protein. It has been shown that the P32T mutant protein possesses reduced stability and about half of the enzyme activity of the wild type enzyme in vitro [12,60]. Recently, it has also been shown that NUDT16 protein has IDP/dIDP-, and to a lesser extent, ITP/dITP-hydrolyzing activity [22,43], which may be responsible for the prevention of ITP/dITP production in vivo. The other hypothesis is that an ITPA deficiency may be related to a specific kind of disease in human populations, 
although this possibility has not yet been sufficiently explored. Recently, Fellay et al reported that in a human population, ITPA enzyme activity was related to a sensitivity to ribavirin, an anti-hepatitis $C$ virus drug [19]. In this case, higher ITPA activity was associated with a higher susceptibility to anaemia caused by ribavirin. Clinical and biochemical analyses of ITPA-deficient patients as well as human ITPA-deficient cells are important for clarifying the biological significance of inosine nucleotides and ITPA protein in humans.

\section{Future perspectives}

There are many issues to be resolved in terms of the biological significance of ITP, dITP and the cellular systems that maintain the quality of canonical nucleotide pools in mammalian cells.

The effects caused by deoxyinosine and inosine in DNA and RNA have not been clearly elucidated as yet. DNA and RNA polymerases are likely to recognize dITP and ITP as dGTP and GTP, then incorporate them opposite C during replication and transcription, respectively $[25,61]$. However, once incorporated into a polynucleotide, hypoxanthine, the base moiety of inosine nucleotides, may pair with $T$ and other bases in addition to $C[61,62]$. These aberrant base pairs may be recognized by the mismatch repair system as well as by the base excision repair system. In addition to its effect as a substrate for replication and transcription, ITP has the potential to interact with the ATP/GTP-binding proteins [28-30]. Most of the processes involving ITP have not been elucidated as yet.

We did not detect ITPA protein in the mitochondrial fraction, although there exist independent nucleotide pools and systems of replication and transcription. It is likely that there is another ITP/dITP clearance system in mitochondria.

We did not discuss XTP and XXTP, which are substrates of mammalian ITPA proteins, because we have not yet quantified the amounts of these nucleotides in vivo. To elucidate the molecular mechanisms of the biological effects of the deaminated nucleotides, precise identification and characterization of the enzymes responsible for the metabolic pathways of these non-canonical nucleotides are required. Quantification of both canonical and non-canonical 
nucleotides, and characterization of the metabolite profiles, representing the amount of each nucleotide, are important for understanding the roles of each nucleotide in specific tissue types, since these vary from tissue to tissue.

Conflict of interest

None of the contributors to this article has any conflicting interest.

Acknowledgments

This work was supported by grants from the Ministry of Education, Culture, Sports, Science and Technology of Japan [20013034 to YN, 20012038 to KS]; the Japan Society for the Promotion of Science [19390114 to DT, 08J03650 to TI] and the Kyushu University Global COE program [YN]. 


\section{References}

[1] K.Y. Hwang, J.H. Chung, S.H. Kim, Y.S. Han, Y. Cho, Structure-based identification of a novel NTPase from Methanococcus jannaschii, Nat. Struct. Biol. 6 (1999) 691-696.

[2] M. Nonaka, D. Tsuchimoto, K. Sakumi, Y. Nakabeppu, Mouse RS21-C6 is a mammalian 2'-deoxycytidine 5'-triphosphate pyrophosphohydrolase that prefers 5-iodocytosine, FEBS. J. 276 (2009) 1654-1666.

[3] D. Tsuchimoto, T. Iyama, M. Nonaka, N. Abolhassani, E. Ohta, K. Sakumi, Y. Nakabeppu, A comprehensive screen system for damaged nucleotide-binding proteins, Mutat. Res. this issue.

[4] S. Lin, A.G. McLennan, K. Ying, Z. Wang, S. Gu, H. Jin, C. Wu, W. Liu, Y. Yuan, R. Tang, Y. Xie, Y. Mao, Cloning, expression, and characterization of a human inosine triphosphate pyrophosphatase encoded by the itpa gene, J. Biol. Chem. 276 (2001) 18695-18701.

[5] M. Behmanesh, K. Sakumi, D. Tsuchimoto, K. Torisu, Y. Ohnishi-Honda, D.E. Rancourt, Y. Nakabeppu, Characterization of the structure and expression of mouse Itpa gene and its related sequences in the mouse genome, DNA Res. 12 (2005) 39-51.

[6] M.Y. Galperin, O.V. Moroz, K.S. Wilson, A.G. Murzin, House cleaning, a part of good housekeeping, Mol. Microbiol. 59 (2006) 5-19.

[7] N.E. Burgis, R.P. Cunningham, Substrate specificity of RdgB protein, a deoxyribonucleoside triphosphate pyrophosphohydrolase, J. Biol. Chem. 282 (2007) 3531-3538.

[8] J.S. Bradshaw, A. Kuzminov, RdgB acts to avoid chromosome fragmentation in Escherichia coli, Mol. Microbiol. 48 (2003) 1711-1725.

[9] V.N. Noskov, K. Staak, P.V. Shcherbakova, S.G. Kozmin, K. Negishi, B.C. Ono, H. Hayatsu, Y.I. Pavlov, HAM1, the gene controlling $6-\mathrm{N}$-hydroxylaminopurine sensitivity and mutagenesis in the yeast Saccharomyces cerevisiae, Yeast 12 (1996) 17-29.

[10] P. Stenmark, P. Kursula, S. Flodin, S. Gräslund, R. Landry, P. Nordlund, H. Schüler, Crystal structure of human inosine triphosphatase. Substrate binding and implication of the inosine triphosphatase deficiency mutation P32T, J. Biol. Chem. 282 (2007) 3182-3187.

[11] C.J. Chern, A.B. MacDonald, A.J. Morris, Purification and properties of a nucleoside triphosphate pyrophosphohydrolase from red cells of the rabbit, J. Biol. Chem. 144 (1969) 5489-5495.

[12] E.I. Stepchenkova, E.R. Tarakhovskaya, K. Spitler, C. Frahm, M.R. Menezes, P.D. Simone, C. Kolar, L.A. Marky, G.E. Borgstahl, Y.I. Pavlov, Functional study of the P32T ITPA variant associated with drug sensitivity in humans, J. Mol. Biol. 392 (2009) 602-613.

[13] D.R. Mbanzibwa, Y. Tian, S.B. Mukasa, J.P. Valkonen, Cassava brown streak virus (Potyviridae) encodes a putative Maf/HAM1 pyrophosphatase implicated in reduction of mutations and a $\mathrm{P} 1$ proteinase that suppresses RNA silencing but contains no HC-Pro, J. Virol. 83 (2009) 6934-6940.

[14] http://ssdb.genome.jp/ssdb-bin/ssdb_best?org_gene=mmu:16434

[15] J. Clyman, R.P. Cunningham, Escherichia coli K-12 mutants in which 
viability is dependent on recA function, J. Bacteriol. 169 (1987) 4203-4210.

[16] B.S. Vanderheiden, C. Zarate-Moyano, Erythrocyte ITP

pyrophosphohydrolase deficiency in a psychiatric population, Biol.

Psychiatry. 11 (1976) 755-765.

[17] S. Sumi, A.M. Marinaki, M. Arenas, L. Fairbanks, M. Shobowale-Bakre, D.C. Rees, S.L. Thein, A. Ansari, J. Sanderson, R.A. De Abreu, H.A. Simmonds, J.A. Duley, Genetic basis of inosine triphosphate pyrophosphohydrolase deficiency, Hum. Genet. 111, (2002) 360-367.

[18] G. Stocco, M.H. Cheok, K.R. Crews, T. Dervieux, D. French, D. Pei, W. Yang, C. Cheng, C.H. Pui, M.V. Relling, W.E. Evans, Genetic polymorphism of inosine triphosphate pyrophosphatase is a determinant of mercaptopurine metabolism and toxicity during treatment for acute lymphoblastic leukemia, Clin. Pharmacol. Ther. 85 (2009) 164-172.

[19] J. Fellay, A.J. Thompson, D. Ge, C.E. Gumbs, T.J. Urban, K.V. Shianna, L.D. Little, P. Qiu, A.H. Bertelsen, M. Watson, A. Warner, A.J. Muir, C. Brass, J. Albrecht, M. Sulkowski, J.G. McHutchison, D.B. Goldstein, ITPA gene variants protect against anaemia in patients treated for chronic hepatitis $\mathrm{C}$, Nature. (2010)

[20] M. Arenas, J. Duley, S. Sumi, J. Sanderson, A. Marinaki, The ITPA c.94C>A and g.IVS2+21A $>C$ sequence variants contribute to missplicing of the ITPA gene, Biochim. Biophys. Acta. 1772 (2007) 96-102.

[21] M. Behmanesh, K. Sakumi, N. Abolhassani, S. Toyokuni, S. Oka, Y.N. Ohnishi, D. Tsuchimoto, Y. Nakabeppu, ITPase-deficient mice show growth retardation and die before weaning, Cell Death Differ. 16 (2009) 1315-1322.

[22] N. Abolhassani, T. lyama, D. Tsuchimoto, K. Sakumi, M. Ohno, M. Behmanesh, Y. Nakabeppu, NUDT16 and ITPA play a dual protective role in maintaining chromosome stability and cell growth by eliminating dIDP/IDP and dITP/ITP from nucleotide pools in mammals, Nucleic Acids Res. 38 (2010) 2891-2903.

[23] C.K. Mathews, DNA precursor metabolism and genomic stability, FASEB. J. 20 (2006) 1300-1314.

[24] F. Taddei, H. Hayakawa, M. Bouton, A. Cirinesi, I. Matic, M. Sekiguchi, M. Radman M, Counteraction by MutT protein of transcriptional errors caused by oxidative damage, Science 278 (1997) 128-130.

[25] M.J. Thomas, A.A. Platas, D.K. Hawley, Transcriptional fidelity and proofreading by RNA polymerase II, Cell, 93 (1998) 627-637.

[26] Y. Nakabeppu, K. Sakumi, K. Sakamoto, D. Tsuchimoto, T. Tsuzuki, Y. Nakatsu, Mutagenesis and carcinogenesis caused by the oxidation of nucleic acids, Biol. Chem. 387 (2006) 373-379.

[27] A. Kornberg, T.A. Baker, The building blocks of DNA synthesis. In: A. Kornberg and T.A. Baker (eds). DNA Replication (2nd ed.) (W. H. Freeman and Company, NY, U.S.A.), (2002) 53-54.

[28] M. Muraoka, H. Fukuzawa, A. Nishida, K. Okano, T. Tsuchihara, A. Shimoda, Y. Suzuki, M. Sato, M. Osumi, H. Sakai, The effects of various GTP analogues on microtubule assembly, Cell Struct. Funct. 24 (1999) 101-109.

[29] M. Muraoka, H. Sakai, Effects of purinenucleotide analogues on 
microtubule assembly, Cell Struct. Funct. 24 (1999) 305-312.

[30] K. Burton, H. White, J. Sleep, Kinetics of muscle contraction and actomyosin NTP hydrolysis from rabbit using a series of metal-nucleotide substrates, J. Physiol. 563 (2005) 689-711.

[31] M.M. LeWinter, G. Osol, Normal physiology of the cardiovascular system, In: V. Fuster, R.W. Alexander, R.A. O'rourke (eds), Hurst's The Heart (10th ed.) (McGraw-Hill Medical Publishing Division, NY, U.S.A.), (2001) 69-73.

[32] A. Moe , J. Ringvoll, L.M. Nordstrand, L. Eide, M. Bjørås, E. Seeberg, T. Rognes, A Klungland, Incision at hypoxanthine residues in DNA by a mammalian homologue of the Escherichia coli antimutator enzyme endonuclease V, Nucleic Acids Res. 31 (2003) 3893-3900.

[33] M. Saparbaev, J. Laval, Excision of hypoxanthine from DNA containing dIMP residues by the Escherichia coli, yeast, rat, and human alkylpurine DNA glycosylases, Proc. Natl. Acad. Sci. USA. 91 (1994) 5873-5877.

[34] M. Saparbaev, J.C. Mani, J. Laval, Interactions of the human, rat, Saccharomyces cerevisiae and Escherichia coli 3-methyladenine-DNA glycosylases with DNA containing dIMP residues, Nucleic Acids Res. 28 (2000) 1332-1339.

[35] B.P. Engelward, G. Weeda, M.D. Wyatt, J.L. Broekhof, J. de Wit, I. Donker, J.M. Allan, B. Gold, J.H. Hoeijmakers, L.D. Samson, Base excision repair deficient mice lacking the Aag alkyladenine DNA glycosylase, Proc. Natl. Acad. Sci. USA. 94 (1997) 13087-13092.

[36] D.R. Duckett, J.T. Drummond, A.I. Murchie, J.T. Reardon, A. Sancar, D.M. Lilley, P. Modrich P, Human MutSalpha recognizes damaged DNA base pairs containing O6-methylguanine, O4-methylthymine, or the cisplatin-d(GpG) adduct, Proc. Natl. Acad. Sci. USA 93 (1996) 6443-6447.

[37] R.R. lyer, A. Pluciennik, V. Burdett, P.L. Modrich, DNA mismatch repair: functions and mechanisms, Chem. Rev. 106 (2006) 302-323.

[38] C. Auclair, A. Gouyette, A. Levy, I. Emerit, Clastogenic inosine nucleotide as components of the chromosome breakage factor in scleroderma patients, Arch. Biochem. Biophys. 278 (1990) 238-244.

[39] W. Vormittag, W. Brannath, As to the clastogenic-, sister-chromatid exchange inducing-and cytotoxic activity of inosine triphosphate in cultures of human peripheral lymphocytes, Mutat. Res. 476 (2001) 71-81.

[40] E. Watrin, J.M. Peters, Cohesin and DNA damage repair, Exp. Cell Res. 312 (2006) 2687-2693.

[41] F. Uhlmann, A matter of choice: the establishment of sister chromatid cohesion, EMBO Rep. 10 (2009) 1095-1102.

[42] H. Matsuzaki, G.A. Kassavetis, E.P. Geiduschek, Analysis of RNA chain elongation and termination by Saccharomyces cerevisiae RNA polymerase III, J. Mol. Biol. 235 (1994) 1173-1192.

[43] T. Iyama, N. Abolhassani, D. Tsuchimoto, M. Nonaka, Y. Nakabeppu, NUDT16 is a (deoxy)inosine diphosphatase, and its deficiency induces accumulation of single-strand breaks in nuclear DNA and growth arrest, Nucleic Acids Res. (2010) in press.

[44] B. Myrnes, P.H. Guddal, H. Krokan, Metabolism of dITP in HeLa cell extracts, incorporation into DNA by isolated nuclei and release of 
hypoxanthine from DNA by a hypoxanthine-DNA glycosylase activity, Nucleic Acids Res. 10 (1982) 3693-3701.

[45] http://www.kegg.com/kegg-bin/show_pathway?map00230

[46] B. Budke, A. Kuzminov A, Production of clastogenic DNA precursors by the nucleotide metabolism in Escherichia coli, Mol. Microbiol. 75 (2010) 230-245.

[47] M.P. Oeschger, M.J. Bessman, Purification and properties of guanylate kinase from Escherichia coli, J. Biol. Chem. 241 (1966) 5452-5460.

[48] A. Hershko , A. Razin, T. Shoshani, J. Mager, Turnover of purine nucleotides in rabbit erythrocytes. II. Studies in vitro, Biochim. Biophys. Acta. 149 (1967) 59-73.

[49] B.S. Vanderheiden, Inosine di- and triphosphate synthesis in erythrocytes and cell extracts, J. Cell. Physiol. 99 (1979) 287-301.

[50] P.C. Dedon, M. Barth, B. Chen, M. DeMott, V. Dendroulakis, M. Dong, S. Kalinga, E. Elmquist, Y. Margolin, B. Pang, X. Zhou, Diverse mechanisms of endogenous nucleobase deamination in DNA and RNA, In Advances in Molecular Toxicology, (2006) ed. J. Fishbein, Wiley, NY.

[51] P. Karran, T. Lindahl, Hypoxanthine in deoxyribonucleic acid: generation by heat-induced hydrolysis of adenine residues and release in free form by a deoxyribonucleic acid glycosylase from calf thymus, Biochemistry 19 (1980) 6005-6011.

[52] S.T. Chung, K. Aida, Purification and properties of ATP deaminase from Microsporum audouini, J. Biochem. 61 (1967) 1-9.

[53] H. Ren, L. Wang, M. Bennett, Y. Liang, X. Zheng, F. Lu, L. Li, J. Nan, M. Luo, S. Eriksson, C. Zhang, X.D. Su, The crystal structure of human adenylate kinase 6: An adenylate kinase localized to the cell nucleus, Proc. Natl. Acad. Sci. USA. 102 (2005) 303-308.

[54] R.P. Agarwal, E.M. Scholar, K.C. Agarwal, R.E.J. Parks, Identification and isolation on a large scale of guanylate kinase from human erythrocytes. Effects of monophosphate nucleotides of purine analogs, Biochem. Pharmacol. 20 (1971) 1341-1354.

[55] P. Nordlund, P. Reichard, Ribonucleotide reductases, Annu. Rev. Biochem. 75 (2006) 681-706.

[56] K.M. Olesen, S.H. Hansen, U. Sidenius, K. Schmiegelow, Determination of leukocyte DNA 6-thioguanine nucleotide levels by high-performance liquid chromatography with fluorescence detection, J. Chromatogr. B. Analyt. Technol. Biomed. Life Sci. 864 (2008) 149-155.

[57] K. Sakumi, Y. Tominaga, M. Furuichi, P. Xu, T. Tsuzuki, M. Sekiguchi, Y. Nakabeppu, Ogg1 knockout-associated lung tumorigenesis and its suppression by Mth1 gene disruption, Cancer Res. 63 (2003) 902-905.

[58] N.E. Burgis, J.J. Brucker, R.P. Cunningham, Repair system for noncanonical purines in Escherichia coli, J. Bacteriol. 185 (2003) 3101-3110.

[59] J.A. Towbin, N.E. Bowles, The failing heart, Nature 415 (2002) 227-233.

[60] G. Herting, K. Barber, M.R. Zappala, R.P. Cunningham, N.E. Burgis, Quantitative in vitro and in vivo characterization of the human P32T mutant ITPase, Biochim. Biophys. Acta. 1802 (2010) 269-274. 
[61] J.H. Chung, J.H. Back, Y.I. Park, Y.S. Han, Biochemical characterization of a novel hypoxanthine/xanthine dNTP pyrophosphatase from Methanococcus jannaschii, Nucleic Acids Res. 29 (2001) 3099-3107.

[62] M. Hill-Perkins, M.D. Jones, P. Karran, Site-specific mutagenesis in vivo by single methylated or deaminated purine bases, Mutat. Res. 162 (1986) 153-163.

[63] http://www.kegg.com/dbget-bin/www_bget?hsa:377841+hsa:953+hsa:956

[64] K.K. Tsuboi, C.H. Chervenka, Adenylate kinase of human erythrocyte. Isolation and properties of the predominant inherited form, J. Biol. Chem. 250 (1975) 132-140. 


\section{Legends to figures}

Figure 1. Typical phenotypes of Itpa ${ }^{-/-}$mice (129SvEv/C57BI/6J mixed genetic background). (A) No ITPase activity was detected in the erythrocyte extract of the Itpa ${ }^{-/-}$mouse. The amount of IMP released from ITP by the erythrocyte extract was determined by HPLC. Itpa ${ }^{+/+}$, open circle; Itpa ${ }^{+/}$, gray circle; Itpa ${ }^{-/}$, closed circle. (B) Itpa ${ }^{-/-}$mice were smaller than Itpa ${ }^{+/+}$and Itpa ${ }^{+/-}$ mice. Ten-day-old male mice from the same litter were compared. (C) The heart of the Itpa ${ }^{-/}$mouse showed hypoplasia. On electron micrographic analysis, microfibrillar disarray was evident in Itpa ${ }^{-/}$mouse heart (10-days-old). (D) Accumulation of ITP in the nucleotide pool of Itpa $^{-/-}$mouse erythrocytes. The peak area corresponding to the accumulated ITP is shown in green. No ITP was evident in Itpa ${ }^{+/+}$and Itpa ${ }^{+/-}$mouse erythrocytes. (Adapted from Behmanesh et al [21] with permission.)

Figure 2. The roles of the ITPA protein in mouse cells. Deaminated purine nucleoside triphosphates, such as ITP and dITP accumulate in the Itpa ${ }^{-/}$cells, because there is no ITPA protein. Quality control of the nucleotide pool is important not only because DNA (I) and RNA (II) are made up of the nucleotides which it supplies, but also because of the biological pathways that require nucleotides for activities (III), such as those involved in muscle contraction and heart development. (Adapted from Behmanesh et al [21] with permission.)

Figure 3. Metabolic pathways for the synthesis of ITP and dITP. The pathways directly related to ITP, IDP, dITP and dIDP are indicated by red arrows. Putative pathways for synthesizing the deaminated nucleotides are numbered in red. The event or enzyme indicated by each number is as follows: (1) deamination, (2) ribonucleotide reductase (EC: 1.17.4.1), (3) nucleoside-diphosphate kinase (EC: 2.7.4.6), (4) ATP-diphosphatase (EC: 3.6.1.5, 3.6.1.6). Because these ATP-diphosphatases have reported as ectonucleotidases in mammals [63], another enzyme may exist to regulate the intracellular nucleotide pool, such as NUDT16 protein, (5) ITP pyrophosphatase 
(EC: 3.6.1.19), (6) NUDT16 protein [22,43,3; reviewed in detail by Tsuchimoto et al, in the same issue], (7) Guanylate kinase (EC: 2.7.4.8). Agarwal et al reported that human erythrocytic guanylate kinase catalyzes a very slow reaction with IMP [54], (8) Adenylate kinase (EC: 2.7.4.3). Although the purified adenylate kinase of human erythrocyte was reported to contain no measurable catalytic activity on IMP [64], recently Ren et al have shown that IMP could be phosphorylated by purified adenylate kinase 6 protein [53], (?) IMP/dIMP kinase (not identified in mammals, yet). Only a portion of the purine nucleotide synthesis pathways related to ITP, IDP, dITP and dIDP are shown. 


\section{ITP pyrophosphatases}

\begin{tabular}{|l|l|l|l|}
\hline & Gene, enzyme & \multicolumn{1}{|c|}{ Phenotype of mutant } & \multicolumn{1}{|c|}{ Reference } \\
\hline Human & $\begin{array}{l}\text { Gene: ITPA (Ch.20p) } \\
\text { Protein:194aa (21.5kDa) }\end{array}$ & $\begin{array}{l}\text { - accumulation of ITP in erythrocytes } \\
\text { - aberrant sensitivities to the } \\
\text { nucleoside antimetabolite drugs, } \\
\text { such as azathioprine and ribavirin }\end{array}$ & {$[4,10,12,13,16-20]$} \\
\hline Mouse & $\begin{array}{l}\text { Gene: Itpa (Ch.2) } \\
\text { Protein:198aa (21.9kDa) }\end{array}$ & $\begin{array}{l}\text { - peri- or postnatal lethality (depends } \\
\text { on the genetic background) } \\
\text { - heart abnormality } \\
\text { - accumulation of ITP in erythrocytes } \\
\text { - accumulation of inosine in RNA, } \\
\text { deoxyinosine in DNA of the Itpa(-/-) } \\
\text { embryo }\end{array}$ & {$[5,21,22]$} \\
\hline Yeast & $\begin{array}{l}\text { Gene: HAM1/YJR069C } \\
\text { Protein:197aa (22.1kDa) }\end{array}$ & $\begin{array}{l}\text { - Increased sensitivity (mutation, } \\
\text { survival) to 6-hydroxylaminopurine }\end{array}$ & {$[9]$} \\
\hline E.coli & $\begin{array}{l}\text { Gene: } \text { rdgB/yggV } \\
\text { Protein:197aa (21.0kDa) }\end{array}$ & $\begin{array}{l}\text { - the synergistic lethality with recA } \\
\text { or with recBC. } \\
\text { rdgB mutants exhibit a hyper- } \\
\text { recombination and SOS-induced } \\
\text { phenotype }\end{array}$ & {$[7,8,15]$} \\
\hline
\end{tabular}


A

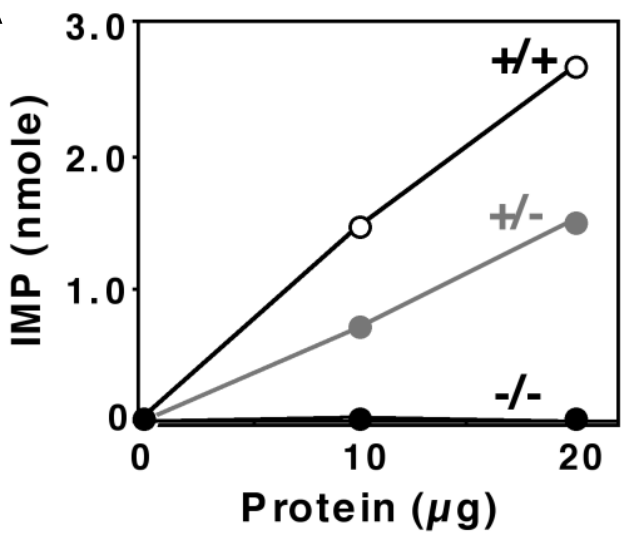

$-/-$

C

macro

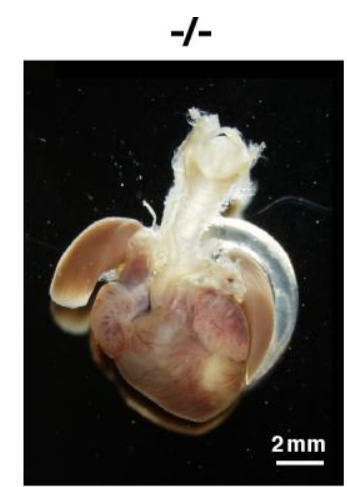

EM
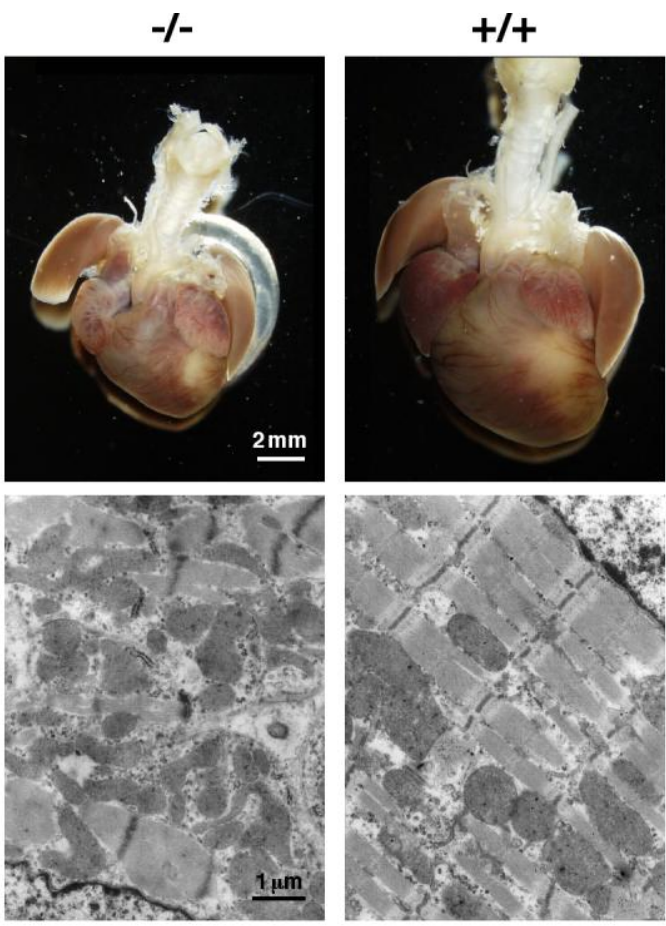

B

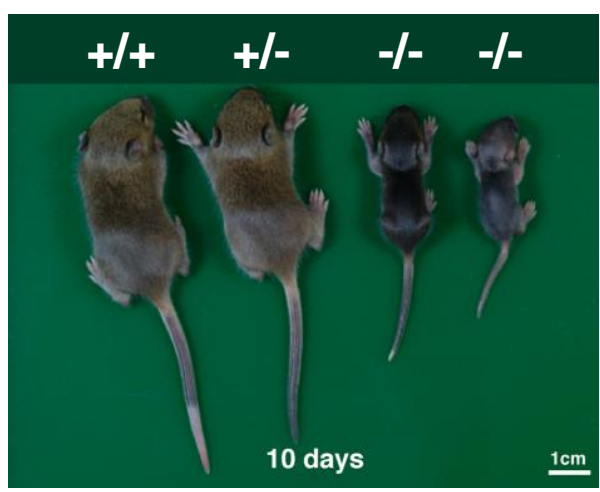

$1 \mathrm{~cm}$
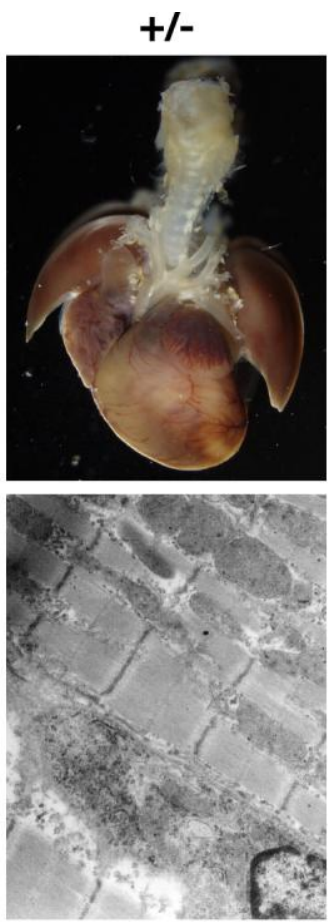

D

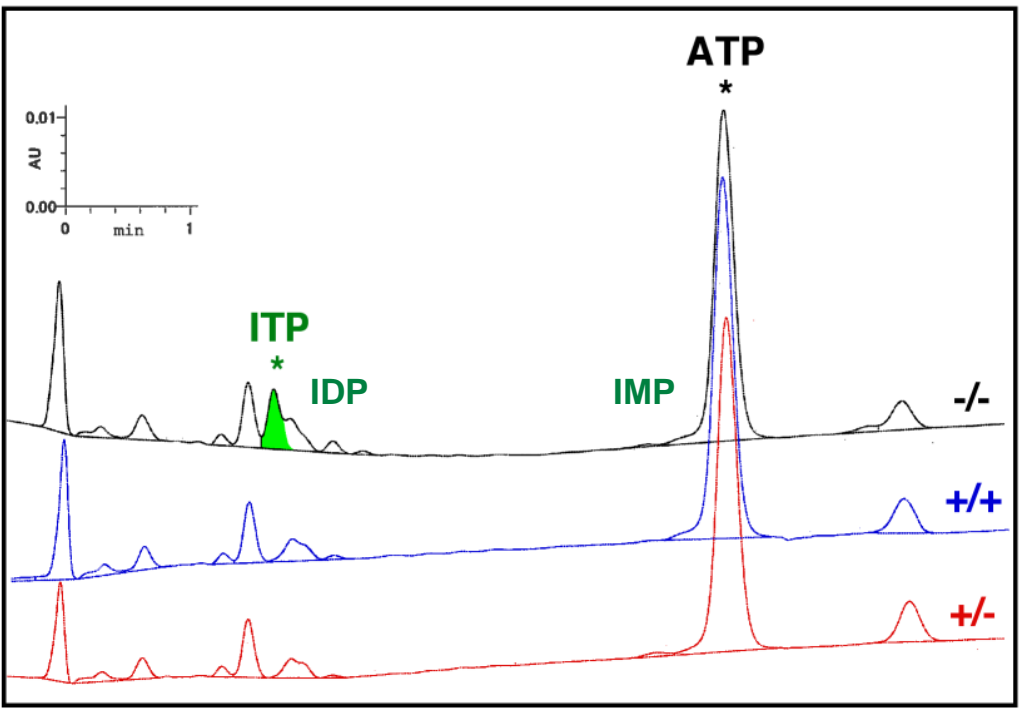

Sakumi et al., Figure 1 


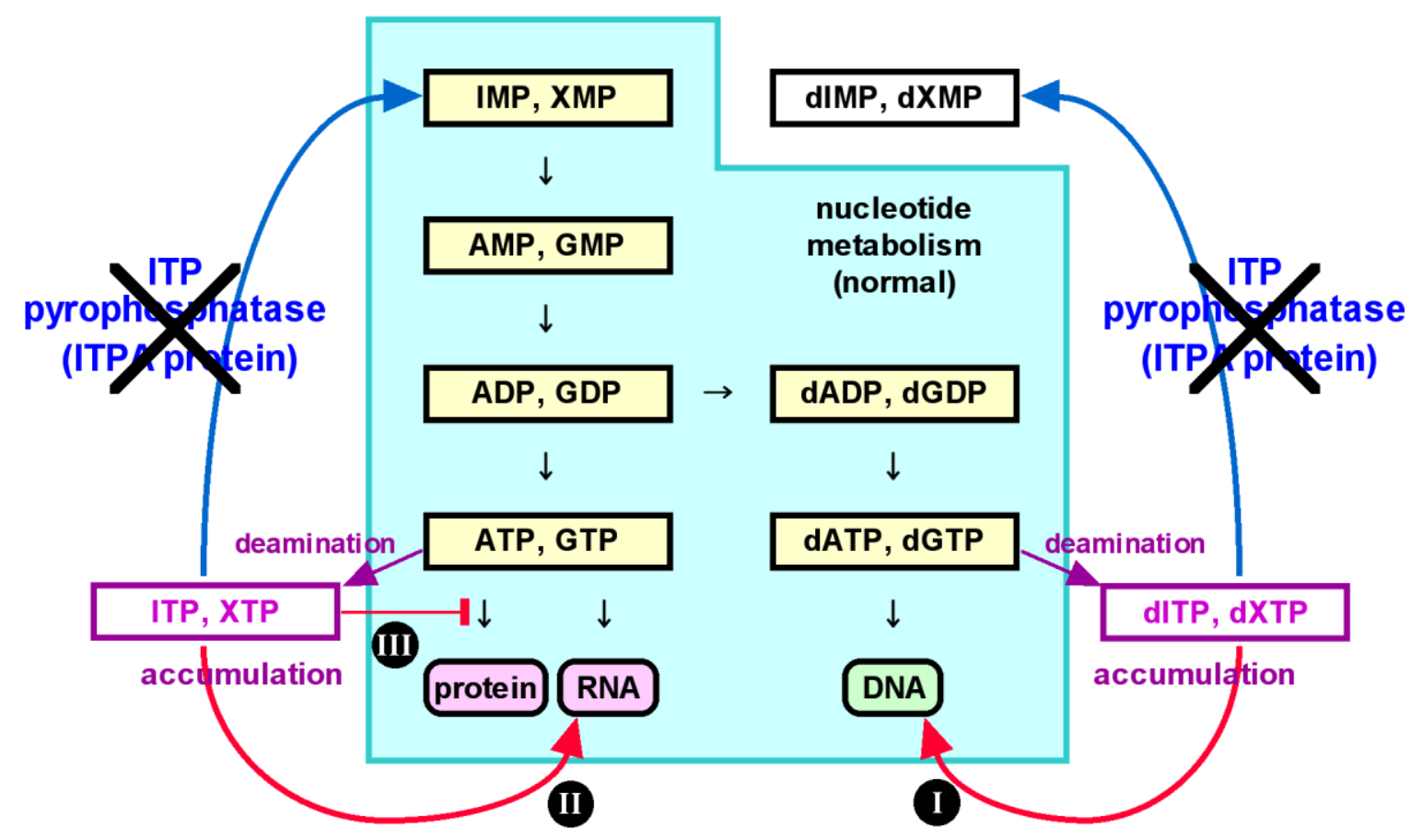

Sakumi et al., Figure 2 


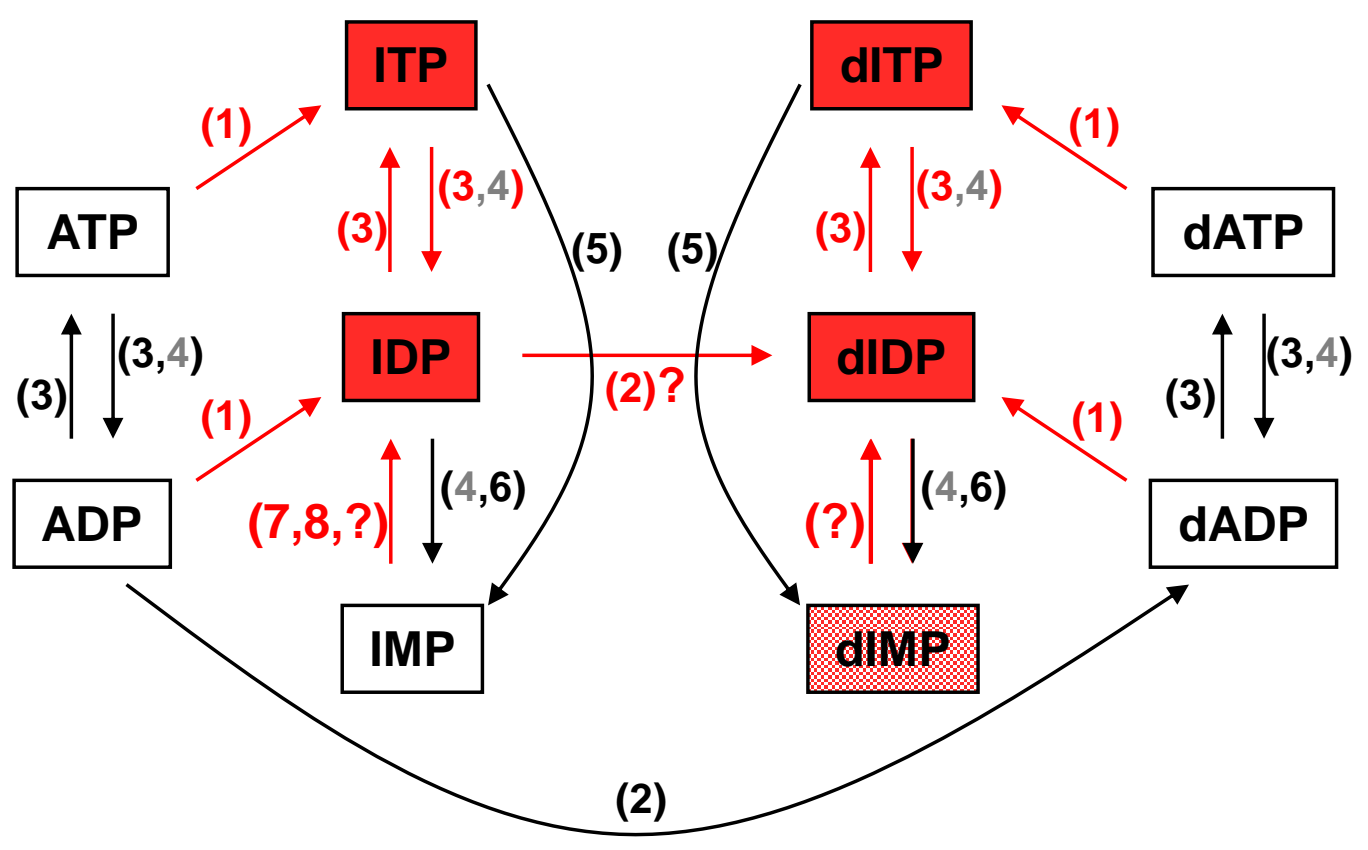

(1) deamination

(2) ribonucleotide reductase (EC: 1.17.4.1)

(3) nucleoside-diphosphate kinase (EC: 2.7.4.6)

(4) ATP-diphosphatase (EC: 3.6.1.5, 3.6.1.6)

(5) ITP pyrophosphatase (EC: 3.6.1.19)

(6) NUDT16 protein

(7) Guanylate kinase (EC: 2.7.4.8)

(8) Adenylate kinase (EC: 2.7.4.3)

(?) IMP/dIMP kinase (not identified yet) 